\title{
DESIGN OF CONTROLLED RELEASE MUCOADHESIVE BUCCAL TABLETS OF IVABRADINE HCL USING SINTERING TECHNIQUE
}

\author{
CHANDAN MOHANTY ${ }^{*}$, K. V. SUBRAHMANYAM ${ }^{2}$
}

${ }^{1}$ Guru Nanak Institutions Technical Campus-School of Pharmacy, Ibrahimpatnam, Hyderabad 501506, Telangana, India, ${ }^{2}$ Siddhartha Institution of Pharmacy, Narapally (V), Ghatkesar (M), Hyderabad 501301, Telangana, India

Email: chandan_mohanty31@rediffmail.com

Received: 29 Apr 2021, Revised and Accepted: 02 Jun 2021

\section{ABSTRACT}

Objective: The objective of the present work was to study the use of the sintering technique, a relatively new concept in pharmaceutical sciences, in the development of mucoadhesive buccal tablets for ivabradine Hydrochloride.

Methods: The method consisted of blending drug, hydroxypropyl methylcellulose (HPMC K100M), carnauba wax, and other excipients followed by direct compression into tablets. The compressed fluffy matrices were sintered at two different constant temperatures like $50{ }^{\circ} \mathrm{C}$ and $60{ }^{\circ} \mathrm{C}$ for two different periods like $1.5 \mathrm{~h}$ and $3 \mathrm{~h}$ in a hot air oven. The effect of sintering on tensile strength, dissolution profile, and other parameters were studied. The drug-polymer-excipient compatibility was evaluated by Fourier transform Infrared (FTIR) and differential scanning calorimetric (DSC) studies.

Results: The sintering condition markedly affected the drug release properties, hardness, and friability of the tablets. Based on the $\mathrm{f}_{2}$ similarity factor value, Ex-vivo mucoadhesive strength, Ex-vivo residence time, and in vitro dissolution studies, formulation F3SD was selected as an optimized formulation. Drug release followed a non-Fickian diffusion mechanism with the Higuchi model release kinetics. Stability studies of mucoadhesive buccal tablets in normal human saliva indicated the stability of the drug and buccal tablet in the oral cavity. Stability studies as per ICH guidelines revealed that optimized formulation was stable on storage conditions.

Conclusion: The sintering technique provides a significant and convenient method for the development of a controlled release dosage form that can be used in the design of mucoadhesive buccal tablets of Ivabradine HCL.

Keywords: Sintering Technique, Mucoadhesive, Ivabradine, Controlled release

(C) 2021 The Authors. Published by Innovare Academic Sciences Pvt Ltd. This is an open access article under the CC BY license (https://creativecommons.org/licenses/by/4.0/) DOI: https://dx.doi.org/10.22159/ijap.2021v13i4.41931. Journal homepage: https://innovareacademics.in/journals/index.php/ijap

\section{INTRODUCTION}

The buccal delivery system involves the administration of the required drug through the buccal mucosal membrane lining of the oral cavity in the mouth. The buccal region of the oral cavity is an attractive site for the administration of the drug of choice [1]. A drug administered through buccal mucosa enters directly into the systemic circulation, hence thereby minimizing the first-pass hepatic metabolism and adverse gastrointestinal effect [2]. Buccal drug absorption can be quickly terminated in cases of toxicity by removing the dosage form from the buccal cavity. It is also possible to administer drugs to patients who cannot be dosed orally to prevent accidental swallowing [3-6]. Buccal mucosa makes a more suitable choice of the site if prolonged drug delivery is desired because adhesion to sites such as oral cavities increases bioavailability by virtue of optimal contact with the adhesive surface which enhances absorption of the drug and prolongs gastric residence. Additionally, there is excellent acceptability, and the drug can be applied, localized, and may be removed easily at any point of time during the treatment period. Hence Bucco-adhesive drug delivery systems have been developed basically to increase the retention of drugs in the oral cavity.

The exploration of the sintering technique in the pharmaceutical field is relatively new, but research interests regarding this concept have been continuously growing. Sintering is defined as the bonding of adjacent particle surfaces in a mass of powder, or in a compact, by the application of heat. The term sintering implies the fusion of particles or the formation of welded bonds among particles of the polymer [7]. Conventional sintering technique involves the heating of compact at a temperature below the melting point of the solid constituents in a controlled environment under atmospheric pressure [8]. The sintering process has been used for the fabrication of sustained-release matrix tablets and the stabilization of the drug permeability of film coatings derived from various pharmaceutical lattices [9]. The concept of the sintering technique was applied in the study of the effect of heating on the mechanical properties of pharmaceutical powders. The changes in the hardness, friability and drug dissolution pattern of tablets stored at elevated temperatures were attributed due to sintering.

In this present investigation, ivabradine was selected as the model drug which is a new class of anti-anginal and anti-ischemic drugs representing a novel pharmacological approach to the treatment of angina. It is categorized as a cardiotonic agent. ivabradine reduces heart rate by selective inhibition of a novel receptor (called as $I_{f}$, funny channel) found on the pacemaker-cell membrane within the SA (sinoatrial) node, a mechanism different from beta-blockers and calcium channel blockers, two commonly prescribed antianginal drugs [10]. When administered orally, ivabradine is absorbed rapidly and almost completely with a peak plasma level reached in about one hour under fasting conditions and in two hours if taken with food [11]. Repeated dosing is needed due to its short elimination half-life of $2 \mathrm{~h}$. Moreover, the drug undergoes high hepatic first-pass metabolism. Hence the systemic bioavailability of ivabradine following oral administration is very low $(40 \%)$ due to the first-pass effect in the gut and liver [10-12]

Since there are very few reports on the applicability of thermal sintering technique on controlled release dosage form, the objective of the present work was to formulate and evaluate Mucoadhesive buccal tablets for ivabradine using the new sintering technique to avoid extensive first-pass metabolism, to prolong the duration of drug action and ultimately to increase the drug bioavailability.

\section{MATERIALS AND METHODS}

\section{Materials}

Gift samples of ivabradine HCL and Carnauba Wax were provided by Glenmark Pvt Ltd., Mumbai. HPMC K100M, Microcrystalline cellulose, Mannitol and Magnesium Stearate, and talc were procured from Lobachem Pvt Ltd Mumbai. All other chemicals and reagents used for the study were of analytical grade. 


\section{Methods}

Calculation of dose of the drug in the sustained release formulations

The formulas involved in the calculation of loading dose, desired rate of drug release, maintenance dose and total dose required for ivabradine sustained release formulation as follows:

Oral dose $\left(\mathrm{X}_{0}\right)=7.5 \mathrm{mg}$, Elimination half-life $\left(\mathrm{t}_{1 / 2}\right)=2 \mathrm{~h}$, Time for sustained action or dosing interval $(\mathrm{T})=12 \mathrm{~h}$, Time to reach peak plasma concentration $\left(\mathrm{t}_{\mathrm{p}}\right)=2 \mathrm{~h}$

Elimination rate constant $(\mathrm{Ke})=0.693 / \mathrm{t}_{1 / 2}=0.693 / 2 \mathrm{~h}=0.346 / \mathrm{h}$

Initial dose $(\mathrm{Di})=\mathrm{Css} . \mathrm{Vd} / \mathrm{F}$, but Css= F. $\mathrm{X}_{0} / \mathrm{Ke} . \mathrm{Vd} . \mathrm{T}$

Hence $\mathrm{Di}=\mathrm{X}_{0} / \mathrm{Ke} . \mathrm{T}=7.5 / 0.346 \times 12=7.5 / 4.152=1.806 \mathrm{mg}$

Desired rate of drug release $(\mathrm{Ks})=\mathrm{Di} \times \mathrm{Ke}=1.806 \times 0.346=0.624$ $\mathrm{mg} / \mathrm{h}$

Maintenance dose $(\mathrm{Dm})=\mathrm{Ks} \times \mathrm{T}=0.624 \times 12=7.499 \mathrm{mg}$
Loading dose $\left(\mathrm{D}_{\mathrm{L}}\right)=\operatorname{Di}-(\mathrm{Ks} \times \mathrm{t} \mathrm{p})=1.806-(0.624 \times 2)=1.806-$ $1.248=0.558 \mathrm{mg}$

Total dose $\left(\mathrm{D}_{\mathrm{T}}\right)=\mathrm{D}_{\mathrm{L}}+\mathrm{Dm}=0.558+7.499=8.057 \mathrm{mg}=8 \mathrm{mg}$

Hence for $12 \mathrm{~h}$ sustained release dosage form, the buccal tablet should contain a total dose of $8 \mathrm{mg}$ of the drug, and it should release $0.558+0.624=1.182 \mathrm{mg}(14.77 \%)$ in the first $\mathrm{h}$ and the remaining dose (8-1.182 mg) in remaining 11 h, i.e., $0.619 \mathrm{mg}$ per $\mathrm{h}$ up to $12 \mathrm{~h}$. Thus, the theoretical drug release profile can be calculated using the above values, which are represented in table 1.

\section{Preparation of mucoadhesive buccal tablets of Ivabradine}

The tablets were prepared by the direct compression method. The measured quantity of drug, polymers, and excipients (as shown in table 2) were mixed homogeneously using mortar and pestle initially for $15 \mathrm{~min}$ and finally in a glass bottle by tumbling action. The mixture was then compressed into tablets using an $8 \mathrm{~mm}$ biconcave punch, 8 stations rotary tablet compression machine (The Rimek Mini Press-1).

Table 1: Theoretical drug release profile

\begin{tabular}{lll}
\hline Time (h) & Total amount of drug release from tablet containing 8 mg of drug (mg) & Cumulative percentage drug release (\%) \\
\hline 1 & 1.182 & 14.77 \\
2 & 1.801 & 22.51 \\
3 & 2.420 & 30.25 \\
4 & 3.039 & 37.98 \\
5 & 3.658 & 45.72 \\
6 & 4.277 & 53.46 \\
7 & 4.896 & 61.20 \\
8 & 5.515 & 68.93 \\
9 & 6.134 & 76.67 \\
10 & 6.753 & 83.41 \\
11 & 7.372 & 92.15 \\
\hline
\end{tabular}

Table 2: Composition of mucoadhesive buccal tablets of Ivabradine

\begin{tabular}{|c|c|c|c|c|}
\hline Ingredients* & F 1 & F 2 & F 3 & F4 \\
\hline Ivabradine HCL & 8 & 8 & 8 & 8 \\
\hline HPMC K100M & 20 & 40 & 60 & 80 \\
\hline Carnauba wax & 80 & 60 & 40 & 20 \\
\hline Micro crystalline cellulose & 23 & 23 & 23 & 23 \\
\hline Mannitol & 14 & 14 & 14 & 14 \\
\hline Magnesium stearate & 3 & 3 & 3 & 3 \\
\hline Talc & 2 & 2 & 2 & 2 \\
\hline Total & 150 & 150 & 150 & 150 \\
\hline
\end{tabular}

*All the ingredients are in milligram per tablet

\section{Sintering of mucoadhesive buccal tablets of Ivabradine}

The prepared tablets were sintered using Hot air oven (Rolex Pvt Ltd., India). The prepared tablets were placed on aluminum foil and exposed to thermal treatment at two different constant temperatures like $50{ }^{\circ} \mathrm{C}$ and $60^{\circ} \mathrm{C}$ for two different periods like $1.5 \mathrm{~h}$ and $3 \mathrm{~h}$ in a hot air oven. The temperature of the oven was maintained at $\pm 1{ }^{\circ} \mathrm{C}$. After sintering (exposing to the respective temperature and time) tablets are removed, cooled to room temperature, and stored in closed desiccators for further use.

Evaluation of Unsintered and Sintered mucoadhesive buccal tablets of Ivabradine

The unsintered and sintered mucoadhesive buccal tablets of ivabradine of all the formulations are evaluated for various parameters like diameter, thickness, hardness, friability, drug content uniformity, microenvironmental $\mathrm{pH}$, bio adhesion studies, percent water uptake study, and in vitro dissolution rate studies.

\section{Physicochemical characteristics of buccal tablet}

The thickness and diameter of the tablets were measured by digital vernier calipers. Prepared tablets were evaluated for hardness by using
Monsanto type hardness tester. The friability test was evaluated using the Roche friability apparatus. Weight variation of tablets was determined by randomly selected twenty tablets and accurately weighed. Results were presented as mean \pm standard deviation (SD).

\section{Drug content uniformity}

Ten tablets were randomly selected from each formulation. The tablets were finely powdered and powder equivalent to the average weight of the tablets was accurately weighed and transferred to 100 $\mathrm{ml}$ volumetric flasks containing $50 \mathrm{ml}$ of phosphate buffer $\mathrm{pH}$ 6.8. To mix the contents the flasks were shaken thoroughly. The volume was made up to $100 \mathrm{ml}$ with phosphate buffer $\mathrm{pH} 6.8$ and filtered. One $\mathrm{ml}$ of the filtrate with suitable dilution was analyzed for ivabradine content at $286.0 \mathrm{~nm}$ using a UV-visible spectrophotometer (Elico 164, India Ltd., Double beam). Estimations were performed in triplicate and their average values were presented.

\section{Mucoadhesive strength studies}

Fresh sheep buccal mucosa was acquired from a local slaughterhouse and was used within $2 \mathrm{~h}$ of slaughter. The sheep buccal mucosa was cut into strips/pieces and washed with 
phosphate buffer pH 6.8 solution. The balance was made adjusted before the study. The mucosal surface facing the upward side was tied to support. The mucoadhesive core side of the tablet was wetted with 2 drops of phosphate buffer $\mathrm{pH} 6.8$ and was stuck to the lower side of the stainless-steel pan by using a bilayered adhesive tape, adhesive side facing downward. The pan was then lowered onto the buccal mucosa, which was tied to support. Then the support with sheep buccal mucosa and buccal tablet were put in contact with each other by pressing with thumb for 5 min to establish an adhesive bond between the buccal tablet and sheep buccal mucosa. Then the weight was increased slowly, till the tablet detached from the mucosal surface. This gave bioadhesion strength of tablets in gm [13].

\section{Percent water uptake study}

Previously weighed prepared tablets were kept in phosphate buffer pH 6.8 for 24 h. After 24 h wet tablets were again weighed and kept for drying. Percent water uptake was calculated by using the following formula [14]

\section{Percent water uptake (\%)}

$$
=\frac{\text { Wet weight }- \text { Remaining dry weight }}{\text { Remaining dry weight }} \times 100
$$

\section{Microenvironment pH}

An acidic or alkaline pH may cause irritation to the buccal mucosa; hence it was determined to keep the surface $\mathrm{pH}$ of the buccal tablets as close to neutral $\mathrm{pH}$ as possible. The microenvironment $\mathrm{pH}$ (surface $\mathrm{pH}$ ) of the tablets was measured (as the method adopted by Bottenberg et al.) [15], in order to investigate the possibility of any side effects in vivo. A combined glass electrode was employed for this purpose. The investigated tablets were allowed to swell by keeping them in contact with $5 \mathrm{ml}$ of distilled water ( $\mathrm{pH} 6.5 \pm 0.05$ ) for $2 \mathrm{~h}$ at room temperature. The $\mathrm{pH}$ was determined by bringing the electrode in contact with the surface of the tablets and allowing it to equilibrate for $1 \mathrm{~min}$.

\section{In vitro dissolution rate study}

In vitro release of ivabradine from unsintered and sintered mucoadhesive buccal tablets was studied using the United States Pharmacopoeia (USP) XXIII dissolution apparatus employing the rotating paddle method. The dissolution medium was used as $200 \mathrm{ml}$ of phosphate buffer $\left(\mathrm{pH}\right.$ 6.8) maintained at $37{ }^{\circ} \mathrm{C} \pm 0.5{ }^{\circ} \mathrm{C}$ and the paddle was rotated at a speed of $50 \mathrm{rpm}$. The buccal tablets were supposed to release the drug from one side of the tablet only; hence a cellophane tape (impermeable backing membrane) was placed on one side of the tablet. The backing layer of the buccal tablet was fixed to the glass slide with cyanoacrylate adhesive (instant adhesive) and immersed into the dissolution media. Aliquots (five ml sample) were withdrawn at a pre-determined time interval and immediately replaced with five $\mathrm{ml}$ of fresh medium $[16,17]$. The samples after filtered through Whatman filter paper (no 40), suitably diluted with fresh dissolution medium (if necessary) analyzed for ivabradine by UV spectrophotometer (Elico 164, India Ltd., Double beam) at $286 \mathrm{~nm}$. The cumulative percentage of drug release was calculated using the standard curve of the drug in phosphate buffer ( $\mathrm{pH} 6.8$ ).

\section{Comparison of dissolution profile and calculation of $f_{2}$ Similarity factor}

The $\mathrm{f}_{2}$ similarity factor given by SUPAC (scale-up and post-approval changes) guidelines for an extended-release dosage form was used as a basis for comparing dissolution profiles. The similarity factor $\mathrm{f}_{2}$ measures the closeness between two profiles. When the two profiles are identical, $f_{2}=100$. An average difference of $10 \%$ at all measured time points results in an $f_{2}$ value of 50 . The Food and Drug Administration (FDA) has set a public standard of $f_{2}$ value between 50 and 100 to suggest a similarity between two dissolution profiles. The dissolution profile of formulations was compared using the $f_{2}$ value, which was calculated by using following the formula

$$
\mathrm{f} 2=50 \times \log \left\{\left[1+\frac{1}{\mathrm{n}} \sum_{\mathrm{t}=1}^{\mathrm{n}}(\mathrm{Rt}-\mathrm{Tt})^{2}\right]^{-0.5} \times 100\right\}
$$

Where ' $n$ ' is the number of sampling points. Whereas Rt and Tt are the cumulative percentages dissolved of the reference (here theoretical dissolution profile of ivabradine) and test profile respectively at time point ' $\mathrm{t}$ ' [17].

\section{Drug release kinetics and mechanism}

The in vitro drug dissolution data obtained was fit into various pharmacokinetic models to explain the release kinetics of ivabradine from mucoadhesive buccal tablets. The obtained dissolution data were plotted as the cumulative percentage amount of drug released vs. time (for zero-order rate), log cumulative percentage amount of drug remaining vs. time (for the first-order rate), the cumulative percentage amount of drug released vs. square root of time (for Higuchi model), cube root of drug percentage remaining in matrix vs. time (for Hixon-Crowell). The correlation coefficient ( $r$ ) for each rate order was calculated. The pharmacokinetic model with the highest correlation coefficient ( $r$ ) was considered to be the most fitting model for dissolution data. Further Korsmeyer and Peppas model (log of cumulative percentage amount released vs. log time) was utilized for the determination of the release mechanism from the polymeric system. According to the Korsmeyer and Peppas equation $\left(\mathrm{Mt} / \mathrm{M}_{\infty}=\mathrm{K}_{\mathrm{K}} . \mathrm{t}{ }^{\mathrm{n}}\right.$, where $\mathrm{Mt} \backslash \mathrm{M} \infty$ : Fraction of drug released at a time ' $t$ ', $K_{k}$ : kinetic rate constant, $n$ : the release exponent) ' $n$ ' value is related to the geometrical shape of the drug delivery system and describes the different drug release mechanism. Value of ' $n$ ' below 0.45 suggests Fickian diffusion mechanism (diffusioncontrolled drug release) and values of ' $n$ ' between 0.45 and 0.89 can be considered as an indicator of non-Fickian diffusion (anomalous transport). Anomalous transport suggests that both diffusions, as well as erosion, were responsible for drug release. If the ' $n$ ' value $=0.89$, it is considered to be non-Fickian case II transport and when 'n' value $>0.89$, it is super case II transport [18-20]

\section{Ex-Vivo residence time}

Ex-Vivo residence time for ivabradine mucoadhesive buccal tablets was determined by using a modified USP disintegrated apparatus. The Disintegration medium consisted of $900 \mathrm{ml}$ of phosphate buffer $\mathrm{pH} 6.8$, maintained at $37^{\circ} \mathrm{C} \pm 1{ }^{\circ} \mathrm{C}$. A segment of fresh sheep buccal mucosa was glued to the glass slide which was then held vertically to the disintegrated apparatus. The prepared buccal tablets were hydrated using $0.5 \mathrm{ml}$ of phosphate buffer $\mathrm{pH} 6.8$ on one side and the hydrated surface was brought in contact with the mucosal membrane. The above glass slide was allowed to move up and then down so that the buccal tablet was completely immersed in the disintegration medium at the lowest point and was out at the highest point. The time taken for complete erosion or detachment of the buccal tablet from the mucosal surface was recorded and repeated thrice $[21,22]$.

\section{Ex-Vivo permeation study}

Ex vivo permeation study of mucoadhesive buccal tablets of ivabradine was carried out on fresh sheep buccal mucosa using modified Franz diffusion cell, with a diffusion area of $17.35 \mathrm{~cm}^{2}$. A semi-permeable membrane (sheep buccal membrane) was mounted between the donor and receptor chambers of the Franz diffusion cell. The receptor chamber was filled with $25 \mathrm{ml}$ of phosphate buffer pH 6.8 and was continuously stirred at $50 \mathrm{rpm}$ using a magnetic stirrer. The diffusion cell was thermostated at $37{ }^{\circ} \mathrm{C} \pm 1{ }^{\circ} \mathrm{C}$. The prepared buccal tablet was placed into the donor chamber of the diffusion cell and was wetted with $1 \mathrm{ml}$ of phosphate buffer $\mathrm{pH}$ 6.8. The samples are withdrawn at a specific time interval from the sampling port and the same volume of fresh phosphate buffer $\mathrm{pH} 6.8$ was replaced into the diffusion cell to maintain the sink condition $[21,23]$. To determine the amount of ivabradine permeated through the membrane, the samples are filtered, suitably diluted, and analyzed by UV spectrophotometer at $286 \mathrm{~nm}$.

\section{Stability of buccal tablets in human saliva}

Stability studies of mucoadhesive buccal tablets of ivabradine were performed in normal human saliva. The human saliva was collected from healthy human volunteers (aged between 18-55years) and filtered through filter paper. Buccal tablets were placed in separate Petri dishes containing $5 \mathrm{ml}$ of human saliva and kept in a 
temperature-controlled oven at $37{ }^{\circ} \mathrm{C} \pm 1{ }^{\circ} \mathrm{C}$ for $6 \mathrm{~h}[23,24]$. At predetermined regular time intervals, the buccal tablets of ivabradine were examined for change in color and shape, the collapse of the tablet, and change in $\mathrm{pH}$. The experiments were repeated in triplicate.

\section{Stability studies}

To assess the drug as well as formulation stability, stability studies were conducted in accordance with ICH guidelines. The optimized formulation was kept in a humidity chamber maintained at 25 ${ }^{\circ} \mathrm{C} / 60 \% \mathrm{RH}$ and $40{ }^{\circ} \mathrm{C} / 75 \% \mathrm{RH}$ for 2 mo. Tablets were analyzed for the different physicochemical parameters i.e., percent drug content, surface $\mathrm{pH}$, percent water uptake study, bioadhesive strength, and percentage of drug release at intervals of $0,30,40,50$, and $60 \mathrm{~d}$.

\section{Drug-polymer-excipient compatibility FTIR studies}

To identify the compatibility between Drug-polymer-excipient, The Fourier transform Infrared (FTIR) studies were performed on the pure drug, drug-polymer mixture, and optimized formulation, using IR spectrophotometer by potassium bromide $(\mathrm{KBr})$ pellet method in the region between the range of 4000 to $400 \mathrm{~cm}^{-1}$.

\section{Differential scanning calorimetric (DSC) studies}

The pure drug i.e., ivabradine HCL and the mixture of drugs with various polymers were subjected to the DSC study. Samples of 2.241 $\mathrm{mg}$ were heated in an atmosphere of nitrogen at a heating rate of 10 ${ }^{\circ} \mathrm{C} / \mathrm{min}$ in a closed aluminum pan over a temperature range from 20 ${ }^{\circ} \mathrm{C}$ to $330{ }^{\circ} \mathrm{C}$. For all the studies nitrogen was used as a pure gas, at the flow rate of $50 \mathrm{ml} / \mathrm{min}$.

\section{Surface morphology (SEM) analysis}

Scanning electron microscopy (SEM) images were studied to determine the morphological changes (surface morphology) of the prepared matrix tablets before and after sintering at 200X magnifications.

\section{RESULTS AND DISCUSSION}

In this present study, the prepared unsintered tablets are exposed to thermal treatment at three different temperatures like $50{ }^{\circ} \mathrm{C}, 60^{\circ} \mathrm{C}$, and $70^{\circ} \mathrm{C}$. But sintering at $70^{\circ} \mathrm{C}$ resulted in slight browning of the prepared tablets. Hence sintering was carried out at $50^{\circ} \mathrm{C}$ and $60^{\circ} \mathrm{C}$ for two different periods like $1.5 \mathrm{~h}$ and $3 \mathrm{~h}$ in a hot air oven. These temperatures were below the melting point of drug ivabradine HCL $\left(198.30^{\circ} \mathrm{C}\right.$, as shown in DSC studies) and polymers $\left(170-180^{\circ} \mathrm{C}\right.$ and 80-88 ${ }^{\circ} \mathrm{C}$ for HPMC [25] and Carnauba wax [25] respectively).

Effect of sintering on physicochemical characteristics of buccal tablet

The effects of sintering conditions on evaluation parameters of unsintered and sintered ivabradine mucoadhesive buccal tablets are shown in table 3 . All the unsintered, as well as thermally sintered formulations of ivabradine mucoadhesive buccal tablets, passed the test for weight uniformity (complied with the pharmacopeial standard for uniformity). The hardness of the prepared tablets mainly affected by the amount of carnauba wax and sintering condition. It was found that with an increase in the amount of wax, sintering time, and sintering temperature, the hardness of the tablets increased. Tablets from all the formulations passed the friability test (less than $0.8 \%$ ), which ensured the mechanical stability of prepared tablets. However, with the sintering conditions, the friability of the tablets was found to be decreased. The increased hardness and decreased friability of the tablets after sintering may be due to the fusion of polymer particles or the formation of the welded bond among the polymer particles at higher temperatures.

The percentage of the drug content was found to be in the range of $96 \%$ to $101 \%$ for all the formulations, hence complying with Indian Pharmacopeia limits for drug content uniformity. Therefore, it was also ascertained that the sintering condition has no significant effects on drug content uniformity from all the formulations.

The measured value of the microenvironment $\mathrm{pH}$ (surface $\mathrm{pH}$ ) of the tablets was found to be in the range of 6.08 to 6.5 , which are near to neutral. Hence the prepared mucoadhesive buccal tablets of ivabradine might not produce any irritation to the buccal mucosa, as the acceptable range for $\mathrm{pH}$ of saliva is 5 to 7 .

The percent water uptake of tablets was observed to be maximum with unsintered tablets. With an increase in sintering time and sintering duration water uptake decreased, which indicates that the hydrophobicity of tablets increased after sintering. This justifies the drug release retardation from the sintered tablets.

Table 3: Evaluated physicochemical parameters of prepared unsintered and sintered mucoadhesive buccal tablets of Ivabradine Note: US: Unsintered; SA: Sintered at $50{ }^{\circ} \mathrm{C}$ for $1.5 \mathrm{~h}, \mathrm{SB}$ : Sintered at $60^{\circ} \mathrm{C}$ for $3 \mathrm{~h}$, SC: Sintered at $60^{\circ} \mathrm{C}$ for $1.5 \mathrm{~h}, \mathrm{SD}$ : Sintered at $60{ }^{\circ} \mathrm{C}$ for $3 \mathrm{~h}$

\begin{tabular}{|c|c|c|c|c|c|}
\hline \multirow[t]{2}{*}{ Formulation code } & \multicolumn{5}{|l|}{ Evaluated parameters } \\
\hline & Hardness* $\left(\mathrm{Kg} / \mathrm{cm}^{2}\right)$ & 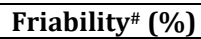 & Drug content ${ }^{@}(\%)$ & Percent water uptake** & Surface $\mathbf{p H}^{* *}$ \\
\hline \multicolumn{6}{|l|}{ Formulation F1 } \\
\hline F1 US & 4.0 & 0.60 & $97.42 \pm 0.30$ & $70 \pm 0.31$ & $6.08 \pm 0.42$ \\
\hline F1 SA & 4.2 & 0.46 & $96.36 \pm 0.07$ & $63 \pm 0.62$ & $6.17 \pm 0.30$ \\
\hline F1 SB & 4.4 & 0.42 & $99.52 \pm 0.34$ & $62 \pm 0.25$ & $6.29 \pm 0.42$ \\
\hline F1 SC & 4.5 & 0.38 & $97.82 \pm 0.16$ & $61 \pm 0.14$ & $6.36 \pm 0.52$ \\
\hline F1 SD & 4.8 & 0.32 & $97.10 \pm 1.07$ & $60 \pm 0.27$ & $6.47 \pm 0.08$ \\
\hline \multicolumn{6}{|l|}{ Formulation F2 } \\
\hline F2 US & 3.8 & 0.63 & $100.12 \pm 0.14$ & $75 \pm 0.33$ & $6.36 \pm 0.32$ \\
\hline F2 SA & 3.9 & 0.47 & $97.14 \pm 0.34$ & $68 \pm 0.64$ & $6.41 \pm 0.15$ \\
\hline F2 SB & 4.1 & 0.44 & $96.42 \pm 0.56$ & $66 \pm 0.35$ & $6.28 \pm 0.30$ \\
\hline F2 SC & 4.3 & 0.40 & $99.07 \pm 0.08$ & $64 \pm 0.06$ & $6.50 \pm 0.17$ \\
\hline F2 SD & 4.4 & 0.38 & $97.44 \pm 0.22$ & $62 \pm 0.21$ & $6.46 \pm 0.76$ \\
\hline \multicolumn{6}{|l|}{ Formulation F3 } \\
\hline F3 US & 3.5 & 0.67 & $94.29 \pm 0.63$ & $83 \pm 0.22$ & $6.32 \pm 0.92$ \\
\hline F3 SA & 3.6 & 0.52 & $96.32 \pm 0.30$ & $72 \pm 0.72$ & $6.01 \pm 0.30$ \\
\hline F3 SB & 3.8 & 0.49 & $98.13 \pm 0.25$ & $69 \pm 0.32$ & $6.21 \pm 0.42$ \\
\hline F3 SC & 3.9 & 0.46 & $96.31 \pm 0.18$ & $66 \pm 0.52$ & $6.10 \pm 0.54$ \\
\hline F3 SD & 4.1 & 0.42 & $97.32 \pm 0.31$ & $64 \pm 0.09$ & $6.48 \pm 0.76$ \\
\hline \multicolumn{6}{|l|}{ Formulation F4 } \\
\hline F4 US & 3.4 & 0.72 & $99.08 \pm 0.24$ & $88 \pm 0.22$ & $6.10 \pm 0.21$ \\
\hline F4 SA & 3.6 & 0.60 & $97.27 \pm 0.71$ & $76 \pm 0.31$ & $6.34 \pm 0.79$ \\
\hline F4 SB & 3.7 & 0.55 & $99.73 \pm 0.39$ & $73 \pm 0.72$ & $6.29 \pm 0.17$ \\
\hline F4 SC & 3.8 & 0.51 & $96.28 \pm 0.57$ & $71 \pm 0.32$ & $6.20 \pm 0.46$ \\
\hline F4 SD & 3.9 & 0.47 & $98.39 \pm 0.42$ & $68 \pm 0.85$ & $6.43 \pm 0.32$ \\
\hline
\end{tabular}

$* n=5, \#: n=10$, @:mean $\pm S D(n=3),{ }^{* *}$ mean $\pm S D(n=3)$. 


\section{Ex-vivo mucoadhesive strength and residence time study}

The mucoadhesive strength and ex-vivo residence time for all the formulations are represented in table 4 . The maximum and minimum mucoadhesive strength from the prepared formulations was found to be $42.8 \mathrm{gm}$ and $17.7 \mathrm{gm}$ respectively. The ex-vivo residence time of ivabradine buccal tablets ranged from $7 \mathrm{~h} 15 \mathrm{~min}$ to $12 \mathrm{~h} 40 \mathrm{~min}$, as this much time was required for mucoadhesive buccal tablets to detach or remove from the buccal mucosa. The bioadhesive strength, as well as ex-vivo residence time of mucoadhesive tablets of ivabradine HCL, was found to be a function of the mucoadhesive polymer concentration.

With the increase in the concentration of mucoadhesive polymer (HPMC K100M), the bioadhesive strength and ex-vivo residence time of tablets were observed to be increased.

Table 4: In vitro mucoadhesive study of buccal tablets of ivabradine

\begin{tabular}{|c|c|c|}
\hline Formulation code & Mucoadhesive strength\# (Gram force) & Ex vivo residence time@ (h) \\
\hline F1 US & $18.8 \pm 0.27$ & $7 \mathrm{~h} 20 \mathrm{~min}$ \\
\hline F1 SA & $18.3 \pm 0.31$ & $7 \mathrm{~h} 22 \mathrm{~min}$ \\
\hline F1 SB & $17.9 \pm 0.42$ & $7 \mathrm{~h} 18 \mathrm{~min}$ \\
\hline F1 SC & $17.8 \pm 0.37$ & $7 \mathrm{~h} 20 \mathrm{~min}$ \\
\hline F1 SD & $17.7 \pm 0.85$ & $7 \mathrm{~h} 15 \mathrm{~min}$ \\
\hline F2 US & $23.7 \pm 0.85$ & $8 \mathrm{~h} 45 \mathrm{~min}$ \\
\hline F2 SA & $23.5 \pm 0.85$ & $8 \mathrm{~h} 40 \mathrm{~min}$ \\
\hline F2 SB & $23.0 \pm 0.23$ & $8 \mathrm{~h} 42 \mathrm{~min}$ \\
\hline F2 SC & $22.8 \pm 0.72$ & $8 \mathrm{~h} 38 \mathrm{~min}$ \\
\hline F2 SD & $22.7 \pm 0.35$ & $8 \mathrm{~h} 44 \mathrm{~min}$ \\
\hline F3 US & $33.7 \pm 0.15$ & $11 \mathrm{~h} 25 \mathrm{~min}$ \\
\hline F3 SA & $33.5 \pm 0.39$ & $11 \mathrm{~h} 24 \mathrm{~min}$ \\
\hline F3 SB & $33.4 \pm 0.73$ & 11 h 23 min \\
\hline F3 SC & $33.2 \pm 0.29$ & $11 \mathrm{~h} 20 \mathrm{~min}$ \\
\hline F3 SD & $33.1 \pm 0.30$ & $11 \mathrm{~h} 21 \mathrm{~min}$ \\
\hline F4 US & $42.8 \pm 0.55$ & $12 \mathrm{~h} 40 \mathrm{~min}$ \\
\hline F4 SA & $42.5 \pm 0.09$ & 12 h 38 min \\
\hline F4 SB & $42.1 \pm 0.32$ & $12 \mathrm{~h} 36 \mathrm{~min}$ \\
\hline F4 SC & $42.0 \pm 0.45$ & 12 h 35 min \\
\hline F4 SD & $42.5 \pm 0.28$ & $12 \mathrm{~h} 36 \mathrm{~min}$ \\
\hline
\end{tabular}

\#: mean $\pm S D(n=3)$, @: Average of three values

\section{In vitro dissolution rate study}

The cumulative percent of drugs released from unsintered and sintered buccal tablets at $50{ }^{\circ} \mathrm{C}, 60^{\circ} \mathrm{C}$ for two different periods like $1.5 \mathrm{~h}$ and $3 \mathrm{~h}$ are represented in fig. 1-4.

The unsintered ivabradine mucoadhesive buccal tablets of formulation FI (formulation code F1US) were able to retard the drug release for $7 \mathrm{~h}$ only, and the maximum release was $96.23 \%$. When the tablets of the same formulation sintered at $50{ }^{\circ} \mathrm{C}$ for $1.5 \mathrm{~h}$ (formulation code $\mathrm{F} 1 \mathrm{SA}$ ) and $3 \mathrm{~h}$ (formulation code F1SB), the maximum release and the time taken to attain maximum release were found to be $96.14 \%, 95.47 \%$, and $10 \mathrm{~h}$ and $11 \mathrm{~h}$, respectively. For tablets of the same formulation at $60^{\circ} \mathrm{C}$ for $1.5 \mathrm{~h}$ (formulation code F1SC) and $3 \mathrm{~h}$ (formulation code F1SD), the maximum release and the time taken to attain maximum release were found to be $95.08 \%, 96.15 \%$, and $12 \mathrm{~h}$ and $13 \mathrm{~h}$, respectively.

The unsintered ivabradine mucoadhesive buccal tablets of formulation F2 (formulation code F2US) were able to retard the drug release for $6 \mathrm{~h}$ only, and the maximum release was $95.42 \%$. When the tablets of the same formulation sintered at $50^{\circ} \mathrm{C}$ for $1.5 \mathrm{~h}$ (formulation code F2SA) and $3 \mathrm{~h}$ (formulation code F2SB), the maximum release and the time taken to attain maximum release were found to be $94.13 \%, 95.02 \%$, and $9 \mathrm{~h}$ and $10 \mathrm{~h}$ respectively. For tablets of the same formulation at $60^{\circ} \mathrm{C}$ for $1.5 \mathrm{~h}$ (formulation code F2SC) and $3 \mathrm{~h}$ (formulation code F2SD), the maximum release and the time taken to attain maximum release were found to be $95.27 \%$, $95.40 \%$, and $11 \mathrm{~h}$ and $12 \mathrm{~h}$, respectively.

The unsintered ivabradine mucoadhesive buccal tablets of formulation F3 (formulation code F3US) were able to retard the drug release for $6 \mathrm{~h}$ only, and the maximum release was $96.31 \%$. When the tablets of the same formulation sintered at $50^{\circ} \mathrm{C}$ for $1.5 \mathrm{~h}$ (formulation code F3SA) and $3 \mathrm{~h}$ (formulation code F3SB), the maximum release and the time taken to attain maximum release were found to be $95.32 \%, 96.26 \%$, and $9 \mathrm{~h}$ and $10 \mathrm{~h}$, respectively. For tablets of the same formulation at $60^{\circ} \mathrm{C}$ for $1.5 \mathrm{~h}$ (formulation code F3SC) and $3 \mathrm{~h}$ (formulation code F3SD), the maximum release and the time taken to attain maximum release were found to be $95.08 \%, 96.37 \%$, and $11 \mathrm{~h}$ and $12 \mathrm{~h}$, respectively.
The unsintered ivabradine mucoadhesive buccal tablets of formulation F4 (formulation code F4US) were able to retard the drug release for $5 \mathrm{~h}$ only, and the maximum release was $95.26 \%$. When the tablets of the same formulation sintered at $50{ }^{\circ} \mathrm{C}$ for $1.5 \mathrm{~h}$ (formulation code F4SA) and $3 \mathrm{~h}$ (formulation code F4SB), the maximum release and the time taken to attain maximum release were found to be $97.24 \%, 95.79 \%$, and $7 \mathrm{~h}$ and $8 \mathrm{~h}$ respectively. For tablets of the same formulation at $60^{\circ} \mathrm{C}$ for $1.5 \mathrm{~h}$ (formulation code $\mathrm{F} 4 \mathrm{SC}$ ) and $3 \mathrm{~h}$ (formulation code F4SD), the maximum release and the time taken to attain maximum release were found to be $96.48 \%$, $96.15 \%$, and $9 \mathrm{~h}$ and $10 \mathrm{~h}$, respectively.

The release of ivabradine from the buccal tablets depended on the ratio of HPMC K100M and carnauba wax, temperature of sintering, and time duration of sintering. The sintering condition markedly affected the release properties of the drug. During dissolution studies, a more sustained release rate of the drug was observed from sintered buccal tablets, compared to the unsintered buccal tablets. As sintering temperature and time duration of sintering of tablets increased the time taken to attain the maximum release of the drug increased correspondingly. An increase in the sintering temperature and/or time of exposure to a particular temperature often decreased the drug release rate. The drug retarding property may be due to the softening of wax particles and the fusion of polymer particles on sintering, forming a continuous sheet around the drug particles in the tablets. This resulted in the entrapment of drug particles in the formed continuous welded bond, which leads to the controlled release of the drug. Furthermore, the drug release rates were also found to be decreased as carnauba wax concentration increased in the formulations. As the amount of wax increased in the tablet, the hydrophobicity of the tablet increased and hence causes a delay in the release of the drug from the tablet.

During the dissolution study, when tablets were examined physically, tablets are found to be swelled initially and were nonerodible over the period of time. At the end of the dissolution study, the shape of the matrix was not altered which indicates that the release of the drug is controlled by diffusion. 


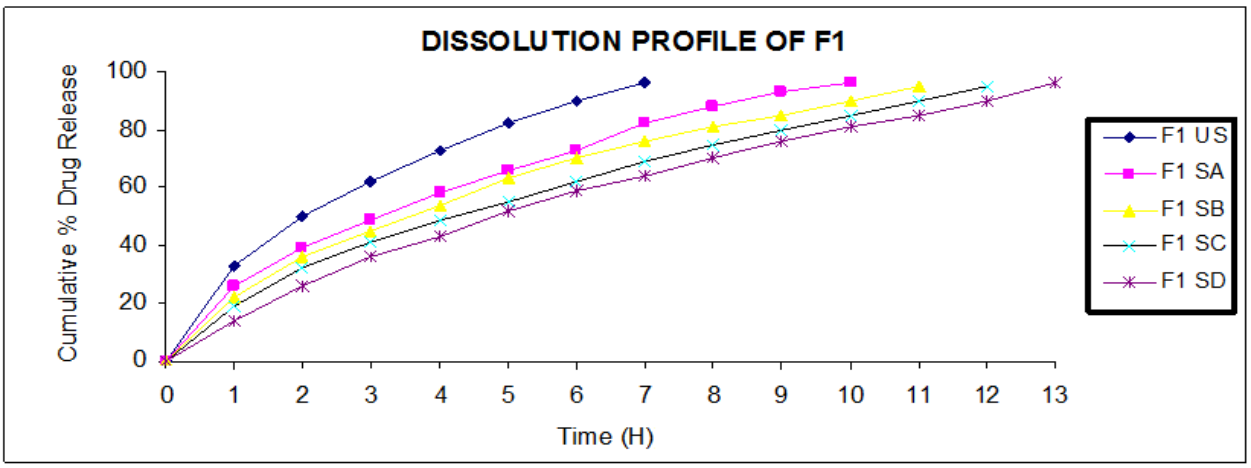

Fig. 1: Dissolution profiles of unsintered and sintered tablets of formulation F1

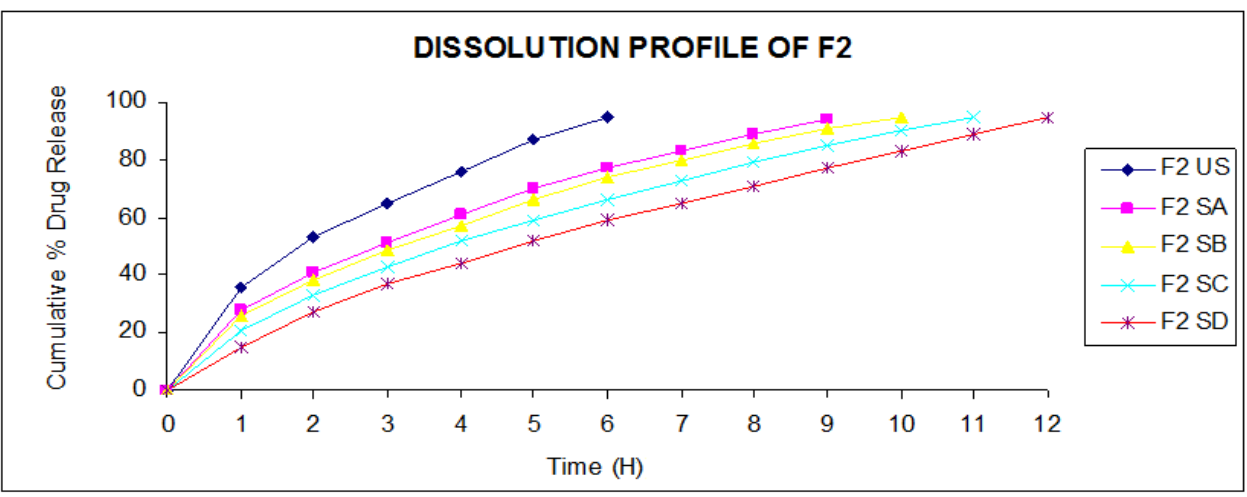

Fig. 2: Dissolution profiles of unsintered and sintered tablets of formulation F2

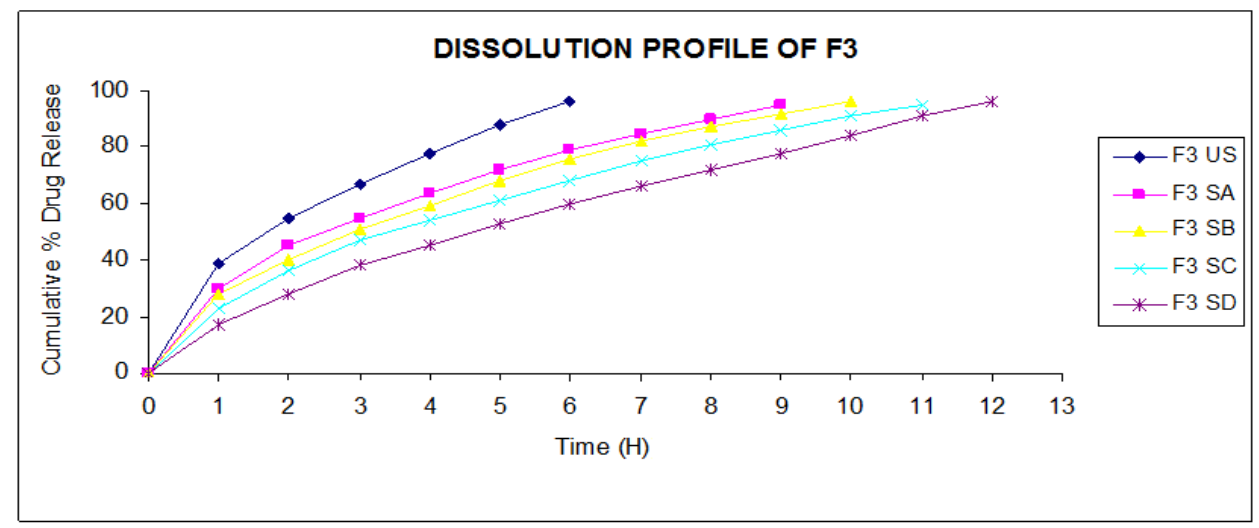

Fig. 3: Dissolution profiles of unsintered and sintered tablets of formulation F3

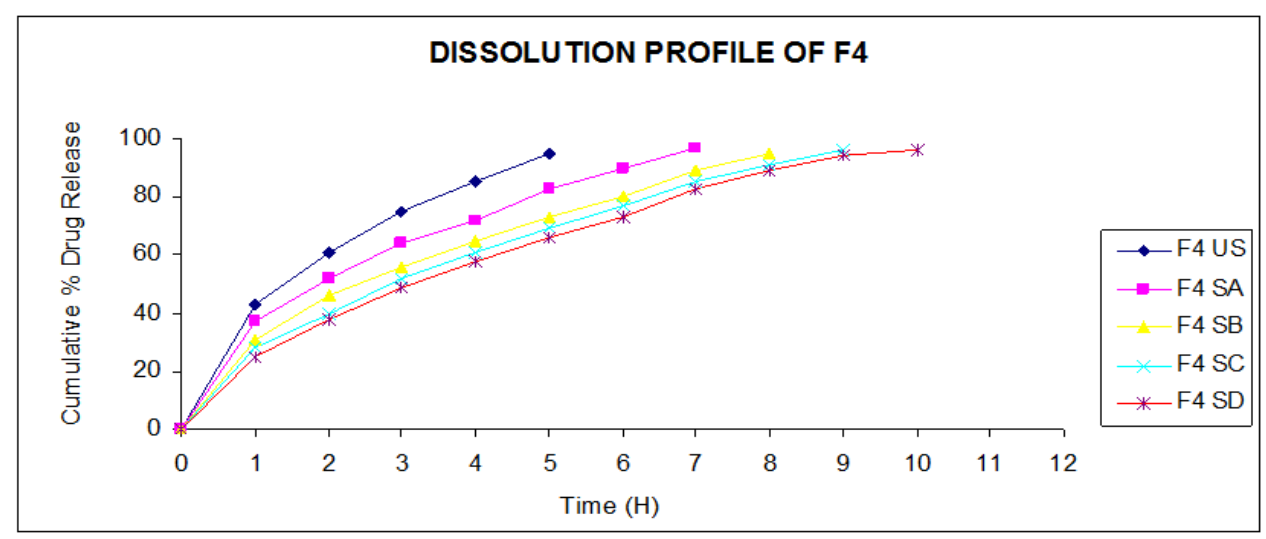

Fig. 4: Dissolution profiles of unsintered and sintered tablets of formulation F4 


\section{Drug release kinetics and mechanism}

The results of In vitro drug release data fitted to various kinetic models and the values of correlation coefficient $\left(\mathrm{r}^{2}\right)$ are presented in table 5 . The ranges of $r^{2}$ values for all the formulations were: zero-order rate (0.9126 to 0.9775$)$, first-order rate (0.9007 to 0.9692$)$, Higuchi model (0.9802 to 0.9999$)$, Hixon-Crowell model (0.9727 to 0.9948 ) and
Korsmeyer-Peppas model (0.9945 to 9997). For both sintered and unsintered tablets, the Higuchi matrix model was found to be the best fit model. The release exponents ' $n$ ' values of the Korsmeyer-Peppas model were in the range of 0.4921 to 0.7290 for all the formulations (both sintered and unsintered), indicating that the release of ivabradine from mucoadhesive buccal tablets followed anomalous non-Fickian diffusion mechanism (as ' $n$ ' values were>0.45).

Table 5: Kinetic parameters of unsintered and sintered matrix tablets of mucoadhesive buccal tablets of Ivabradine

\begin{tabular}{|c|c|c|c|c|c|c|}
\hline \multirow{2}{*}{$\begin{array}{l}\text { Formulation code } \\
\text { Formulation F1 }\end{array}$} & \multirow[t]{2}{*}{ Zero order $\left(r^{2}\right)$} & \multirow[t]{2}{*}{ First order $\left(\mathrm{r}^{2}\right)$} & \multirow[t]{2}{*}{ Higuchi $\left(\mathrm{r}^{2}\right)$} & \multirow[t]{2}{*}{ Hixon crowell $\left(\mathrm{r}^{2}\right)$} & \multicolumn{2}{|c|}{ Koresmeyerpeppas (r) (n) } \\
\hline & & & & & & \\
\hline F1 US & 0.9260 & 0.9551 & 0.9985 & 0.9931 & 0.9985 & 0.5509 \\
\hline F1 SA & 0.9443 & 0.9535 & 0.9954 & 0.9924 & 0.9991 & 0.5779 \\
\hline F1 SB & 0.9404 & 0.9602 & 0.9951 & 0.9932 & 0.9962 & 0.6036 \\
\hline F1 SC & 0.9601 & 0.9410 & 0.9918 & 0.9877 & 0.9980 & 0.6346 \\
\hline F1 SD & 0.9690 & 0.9173 & 0.9837 & 0.9817 & 0.9945 & 0.7290 \\
\hline \multicolumn{7}{|l|}{ Formulation F2 } \\
\hline F2 US & 0.9307 & 0.9512 & 0.9986 & 0.9894 & 0.9996 & 0.5415 \\
\hline F2 SA & 0.9362 & 0.9692 & 0.9976 & 0.9942 & 0.9993 & 0.5580 \\
\hline F2 SB & 0.9413 & 0.9642 & 0.9963 & 0.9948 & 0.9990 & 0.5738 \\
\hline F2 SC & 0.9595 & 0.9446 & 0.9918 & 0.9894 & 0.9973 & 0.6243 \\
\hline F2 SD & 0.9775 & 0.9159 & 0.9802 & 0.9779 & 0.9975 & 0.7239 \\
\hline \multicolumn{7}{|l|}{ Formulation F3 } \\
\hline F3 US & 0.9166 & 0.9437 & 0.9999 & 0.9870 & 0.9997 & 0.5042 \\
\hline F3 SA & 0.9161 & 0.9684 & 0.9993 & 0.9923 & 0.9984 & 0.5224 \\
\hline F3 SB & 0.9308 & 0.9593 & 0.9979 & 0.9939 & 0.9987 & 0.5467 \\
\hline F3 SC & 0.9448 & 0.9566 & 0.9962 & 0.9922 & 0.9983 & 0.5877 \\
\hline F3 SD & 0.9766 & 0.9007 & 0.9822 & 0.9727 & 0.9995 & 0.6897 \\
\hline \multicolumn{7}{|l|}{ Formulation F4 } \\
\hline F4 US & 0.9058 & 0.9625 & 0.9997 & 0.9895 & 0.9995 & 0.4921 \\
\hline F4 SA & 0.9126 & 0.9284 & 0.9996 & 0.9837 & 0.9992 & 0.4962 \\
\hline F4 SB & 0.9309 & 0.9425 & 0.9986 & 0.9843 & 0.9992 & 0.5326 \\
\hline F4 SC & 0.9452 & 0.9413 & 0.9960 & 0.9889 & 0.9991 & 0.5712 \\
\hline F4 SD & 0.9467 & 0.9548 & 0.9931 & 0.9921 & 0.9983 & 0.5985 \\
\hline
\end{tabular}

\section{Selection of optimized formulation}

The $\mathrm{f}_{2}$ Similarity factor of all the formulations was calculated by taking the theoretical dissolution profile of ivabradine as reference. Among all the formulations, only formulations coded with F1SC, F1SD, F2SD, and F3SD showed $f_{2}$ similarity factor value more than 50 (generally similarity factor in the range of $50-100$ is acceptable according to US FDA). The $\mathrm{f}_{2}$ Similarity factor values were found to be $56.31,63.98,67.07$, and 64.52 for formulation code F1SC, F1SD, F2SD, and F3SD respectively (shown in table 6). The various dissolution parameters such as the maximum release of the drug, time to attain maximum release, dissolution rate for all the formulations are also presented in table 6. Though formulation F2SD showed maximum $\mathrm{f}_{2}$ similarity factor value, formulation F3 SD was selected as optimized formulation, based on a higher percentage of drug release $\left(96.37 \%\right.$ in $12 \mathrm{~h}$ at dissolution rate of $8.03 \% \mathrm{~h}^{-1}$ ), sufficient Mucoadhesive strength $(33.1 \pm 0.30 \mathrm{gm})$, higher ex-vivo residence time ( $11 \mathrm{~h} 21 \mathrm{~min}$ ), satisfactory $\mathrm{f}_{2}$ similarity factor value of 64.52 and acceptable surface pH $(6.48 \pm 0.76)$.

Table 6: Dissolution parameters and $f_{2}$ Similarity factor of mucoadhesive buccal tablets of Ivabradine

\begin{tabular}{|c|c|c|c|c|}
\hline Formulation code & Maximum release of drug (\%) & Time to attain maximum release (h) & Dissolution rate $\left(\% h^{-1}\right)$ & $\begin{array}{l}f_{2} \text { Similarity } \\
\text { factor }\end{array}$ \\
\hline F1 US & 96.23 & 7 & 13.74 & 24.61 \\
\hline F1 SA & 96.14 & 10 & 9.61 & 37.42 \\
\hline F1 SB & 95.47 & 11 & 8.67 & 44.69 \\
\hline F1 SC & 95.08 & 12 & 7.92 & 56.31 \\
\hline F1 SD & 96.15 & 13 & 7.39 & 63.98 \\
\hline F2 US & 95.42 & 6 & 15.90 & 22.54 \\
\hline F2 SA & 94.13 & 9 & 10.45 & 34.26 \\
\hline F2 SB & 95.02 & 10 & 9.50 & 38.37 \\
\hline F2 SC & 95.27 & 11 & 8.66 & 48.84 \\
\hline F2 SD & 95.40 & 12 & 7.95 & 67.07 \\
\hline F3 US & 96.31 & 6 & 16.05 & 21.53 \\
\hline F3 SA & 95.32 & 9 & 10.59 & 31.92 \\
\hline F3 SB & 96.26 & 10 & 9.62 & 36.29 \\
\hline F3 SC & 95.08 & 11 & 8.64 & 44.98 \\
\hline F3 SD & 96.37 & 12 & 8.03 & 64.52 \\
\hline F4 US & 95.26 & 5 & 19.05 & 18.68 \\
\hline F4 SA & 97.24 & 7 & 13.89 & 23.91 \\
\hline F4 SB & 95.79 & 8 & 11.97 & 29.75 \\
\hline F4 SC & 96.48 & 9 & 10.72 & 33.69 \\
\hline F4 SD & 96.15 & 10 & 9.61 & 37.22 \\
\hline
\end{tabular}




\section{Ex-vivo permeation study}

The optimized formulation F3SD was subjected to an ex-vivo buccal permeation study on fresh sheep buccal mucosa using modified Franz diffusion cell. The results of the ex vivo permeation study of mucoadhesive buccal tablets of ivabradine revealed that ivabradine was released from the tablet and permeated through sheep buccal membrane and could perhaps permeate through the human buccal mucous membrane. The drug permeation from the mucoadhesive buccal tablet through the sheep buccal mucosa was observed to be steady and $81.6 \%$ of ivabradine permeated in $12 \mathrm{~h}$

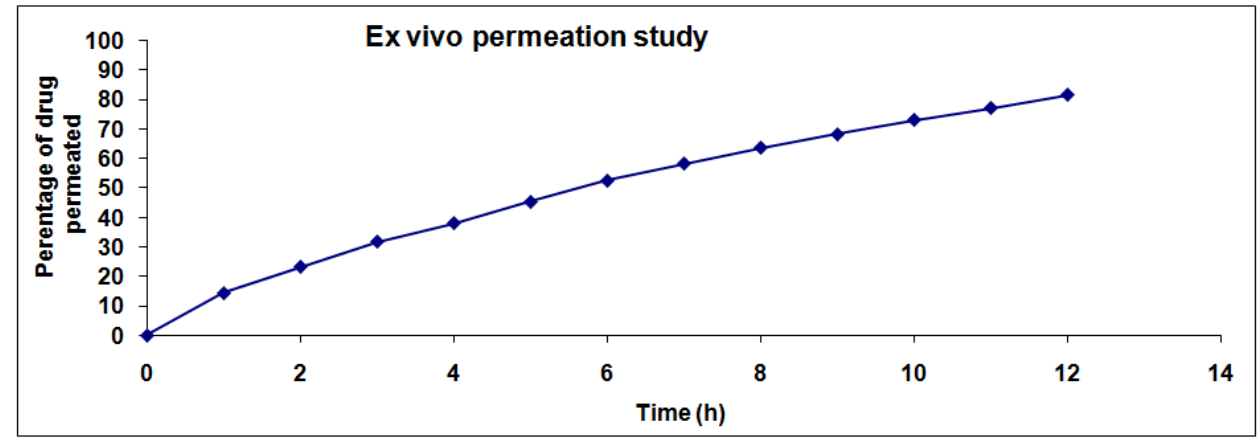

Fig. 5: Ex vivo permeation study of formulation F3SD

\section{Stability of buccal tablets in human saliva}

The Stability studies of buccal tablets in human saliva would be more accurate to mimic the stability of mucoadhesive buccal tablets of ivabradine in the oral cavity in vivo. The Stability studies of optimized formulation in normal human saliva exhibited no change in the color of the mucoadhesive buccal tablets of ivabradine, which would have occurred if the drug was unstable in human saliva, suggesting satisfactory stability of the drug and buccal tablet in the human saliva. Physical properties of the prepared tablets such as thickness and diameter changed slightly owing to the swelling of the polymers in human saliva. But buccal tablets did not collapse in human saliva till the end of the study, ensuring that the buccal tablet strength was sufficient. The results of the Stability studies of buccal tablets in human saliva are shown in table 7.

Table 7: Stability data of formulation F3 SD in human saliva

\begin{tabular}{|c|c|c|c|c|c|}
\hline Time (H) & Color change\# & Thickness* (mm) & Change in diameter* (mm) & Change in $\mathrm{pH}^{*}$ & Collapsing\# \\
\hline 0 & No & 3.42 & 8.01 & 6.48 & -- \\
\hline 1 & No & 3.49 & 8.15 & 6.46 & No \\
\hline 2 & No & 3.54 & 8.28 & 6.50 & No \\
\hline 3 & No & 3.59 & 8.57 & 6.48 & No \\
\hline 6 & No & 3.65 & 8.72 & 6.47 & No \\
\hline 8 & No & 3.83 & 8.91 & 6.46 & No \\
\hline 10 & No & 3.94 & 9.08 & 6.48 & No \\
\hline 12 & No & 4.06 & 9.2 & 6.49 & No \\
\hline
\end{tabular}

\#Visual observation, ${ }^{*}$ Mean of 3 readings

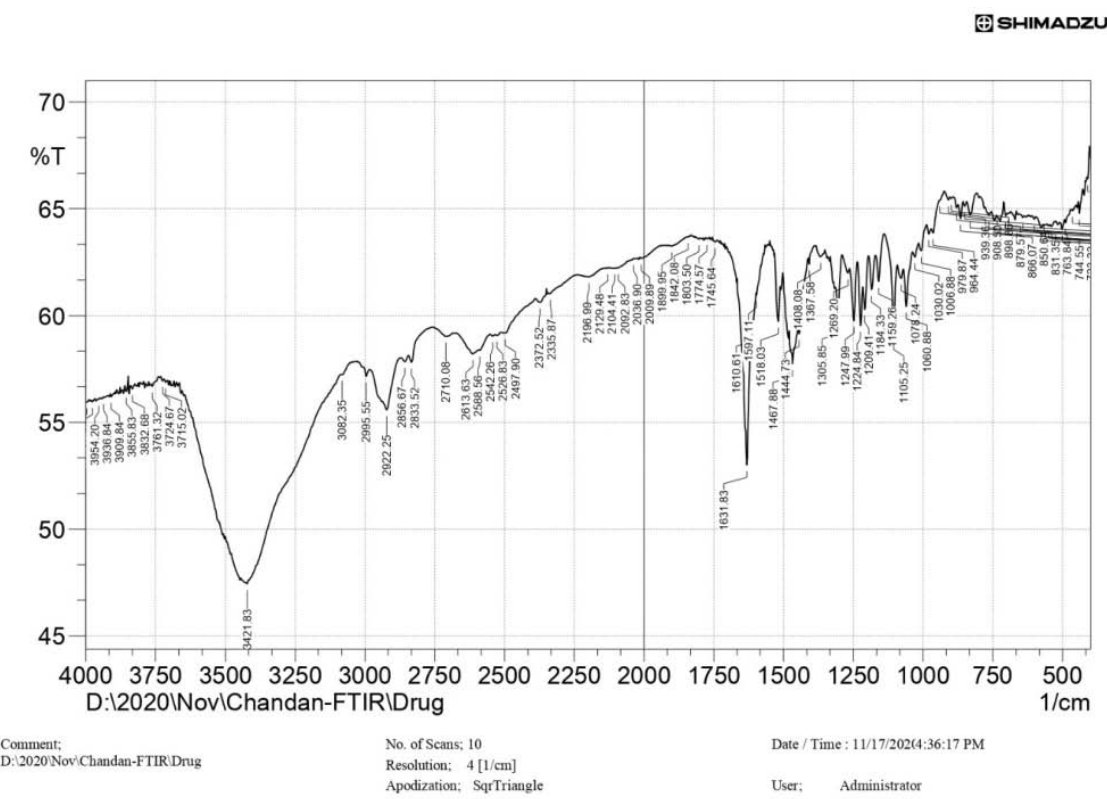


Fig. 6: FTIR spectrum of drug (Ivabradine HCL)

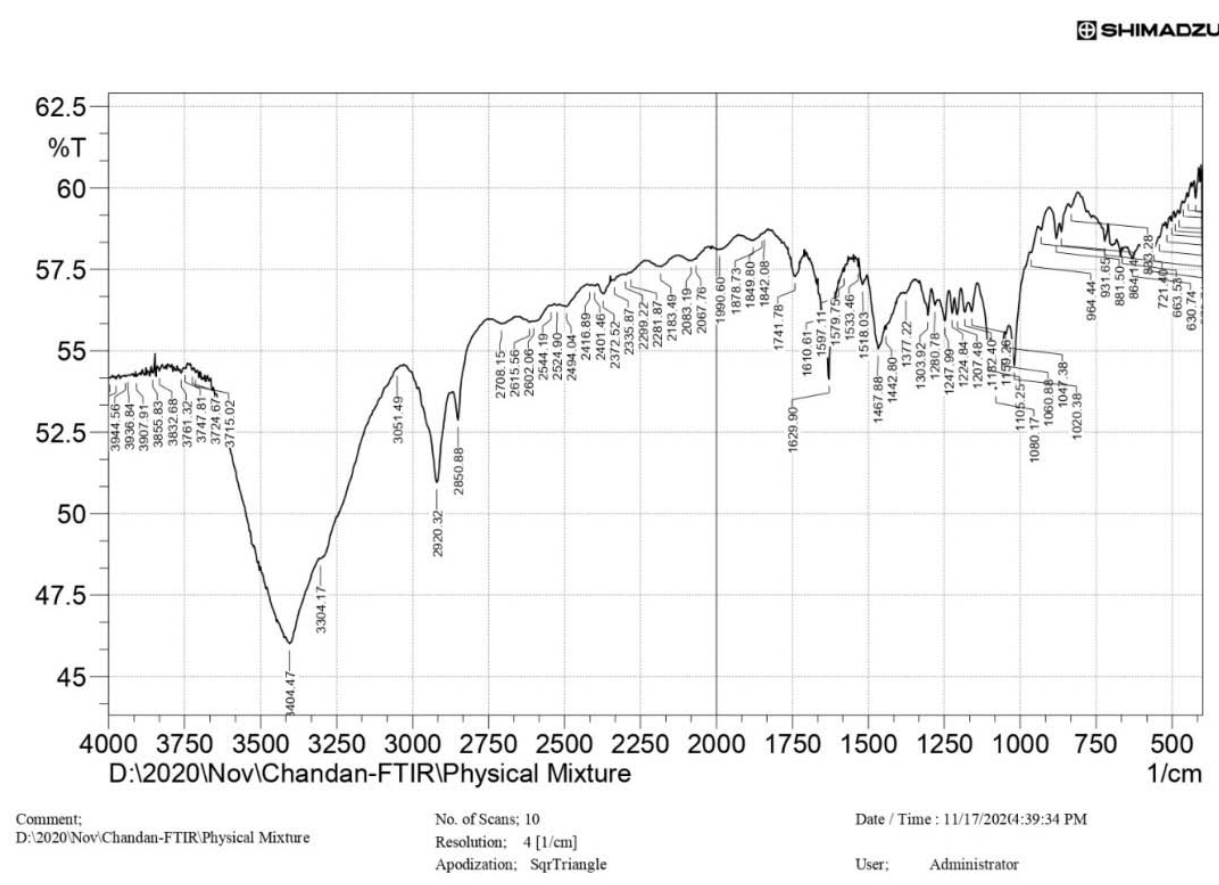

Fig. 7: FTIR spectrum of physical mixture of Ivabradine HCL, HPMC K100M, MCC, Carnauba wax, and mannitol

\section{FTIR studies}

The FTIR spectrum of ivabradine was compared with FTIR spectra of physical the mixture of the drug (ivabradine), Polyethylene oxide, carnauba wax, microcrystalline cellulose, and Mannitol (fig. 6-7). The FTIR spectrum of pure drug ivabradine HCL showed many intense, sharp absorption peaks at 1247.99, 1060.88 (O-CH3 stretching), 1631.83 (C=0 stretching), 2922.25 (symmetric $\mathrm{CH}$ stretching), 1060.88 (C-N stretching of tertiary aliphatic amine), 1518.03 ( $\mathrm{C}=\mathrm{C}$ stretching), and 3421.83 (stretching $\mathrm{N}-\mathrm{H}$ ). The FTIR spectra of the physical mixture showed all the above identical characteristic peaks of ivabradine HCL with minor shifts, indicating no chemical interaction or modification between the drug and polymers.

\section{Differential scanning calorimetric (DSC) studies}

Thermal analysis (DSC studies) was used to examine the thermal behavior of pure drug and the mixture of drugs with various polymers. The DSC thermogram of pure drug ivabradine and drugpolymer physical mixture of optimized formulation was represented in fig. 8 and 9. The thermograms of ivabradine HCL and drugpolymer physical mixture exhibited a sharp endothermic peak at $198.30^{\circ} \mathrm{C}$ and $167.30^{\circ} \mathrm{C}$ respectively, which corresponds to their melting points. A decrease in the energy change of melting endotherm of the drug-polymer physical mixture was observed, which may be due to the slight physical interaction or intimate mixing of the drug and polymer without any chemical interaction $[26,27]$.

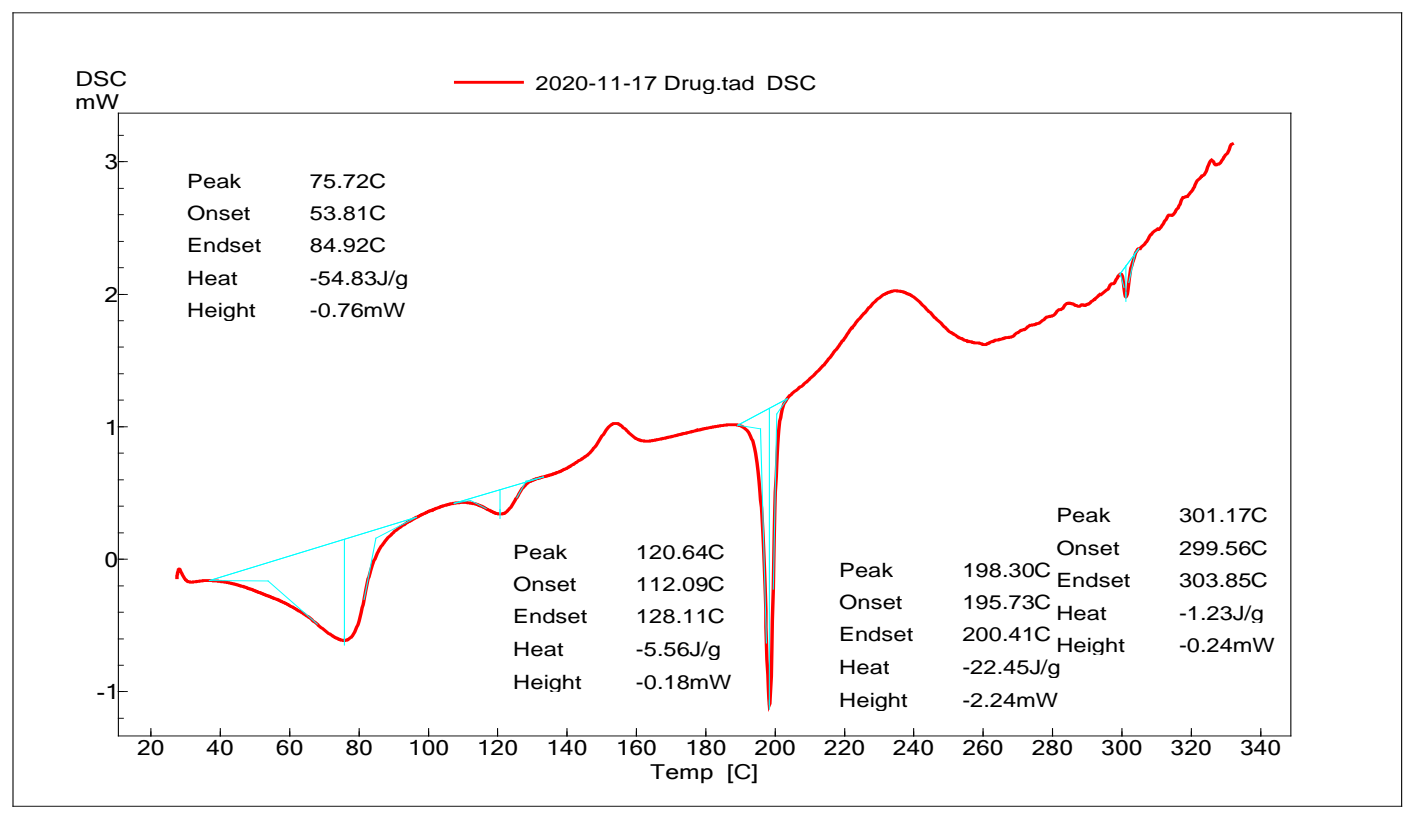


Fig. 8: DSC thermogram of pure drug Ivabradine HCL

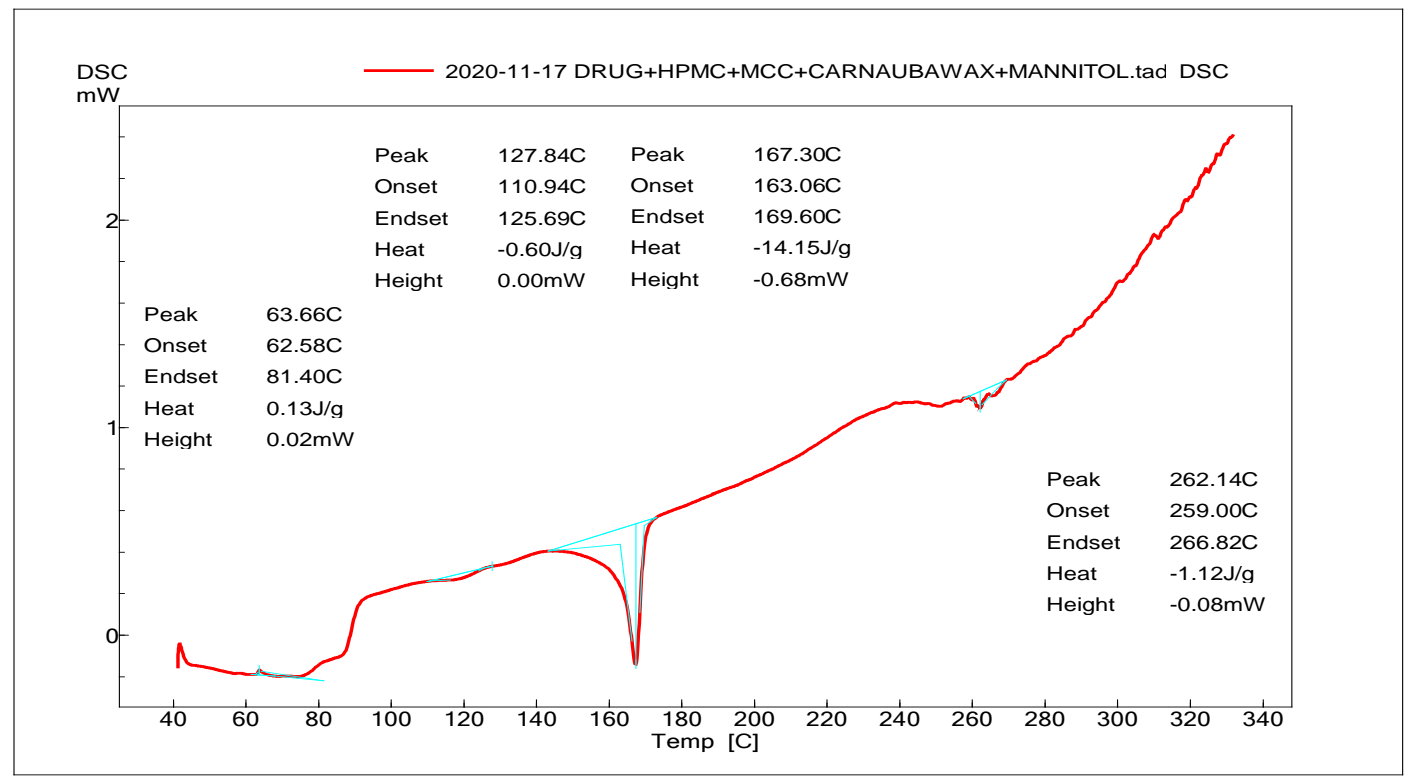

Fig. 9: DSC thermogram of drug-polymer physical Mixture of optimized formulation

\section{Surface morphology (SEM) analysis}

SEM (Scanning electron microscopy) micrographs of tablet surface of optimized formulation (both before and after sintering) were shown in fig. 10. SEM micrographs of sintered tablet surface seemed smoother and displayed that a thin film structure covers the tablet surface. This might be due to the fusion of polymer particles due to sintering conditions and uniform redistribution of the polymer in the pores of the tablet.

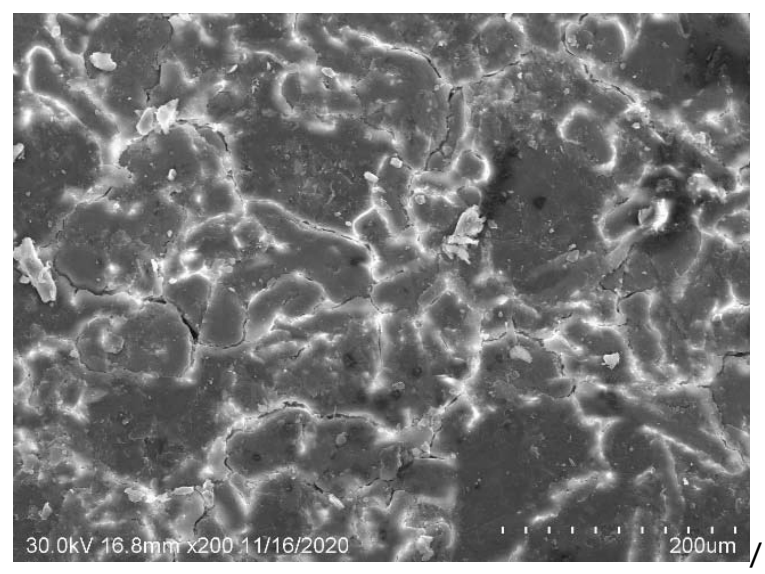

A

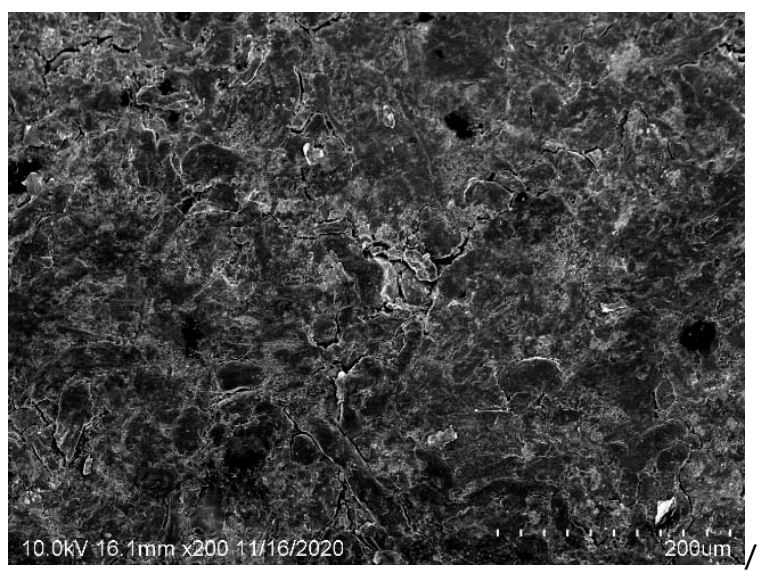

B 
Fig. 10: SEM micrographs of (A) unsintered (B) sintered tablet surface of optimized formulation

\section{Stability studies}

The stability studies of optimized formulation (F3SD) were conducted as per the ICH guidelines (stored at $25^{\circ} \mathrm{C} / 60 \% \mathrm{RH}$ and $40{ }^{\circ} \mathrm{C} / 75 \% \mathrm{RH}$ for $2 \mathrm{mo}$ ). Tablets were withdrawn and retested for the different physicochemical parameters i.e., percent drug content, surface $\mathrm{pH}$, percent water uptake, bioadhesive strength, Ex-Vivo residence time, and percentage of drug release at an interval of $0,30,40,50$, and $60 \mathrm{~d}$. The results are represented in table 8 . The results of the stability studies revealed no significant changes in physicochemical parameters on storage conditions. Hence the formulated mucoadhesive buccal tablets of ivabradine were considered to be stable.

Table 8: Stability study of optimized formulation

\begin{tabular}{|c|c|c|c|c|c|}
\hline \multirow[t]{3}{*}{ Physicochemical parameters } & \multicolumn{5}{|l|}{ Time (Days) } \\
\hline & $\mathbf{0}$ & 30 & 40 & 50 & 60 \\
\hline & $\begin{array}{l}25 \pm 2{ }^{\circ} \mathrm{C} \\
60 \pm 5 \% \mathrm{RH}\end{array}$ & $\begin{array}{l}25 \pm 2{ }^{\circ} \mathrm{C} \\
60 \pm 5 \% \mathrm{RH}\end{array}$ & $\begin{array}{l}40 \pm 2{ }^{\circ} \mathrm{C} \\
75 \pm 5 \% \mathrm{RH}\end{array}$ & $\begin{array}{l}25 \pm 2{ }^{\circ} \mathrm{C} \\
60 \pm 5 \% \mathrm{RH}\end{array}$ & $\begin{array}{l}40 \pm 2{ }^{\circ} \mathrm{C} \\
75 \pm 5 \% \mathrm{RH}\end{array}$ \\
\hline Drug content $(\%)$ & 97.32 & 96.25 & 97.48 & 95.28 & 96.38 \\
\hline Surface $\mathrm{pH}$ & 6.48 & 6.46 & 6.49 & 6.46 & 6.45 \\
\hline Bio adhesive strength (gm) & 33.1 & 33.2 & 33.3 & 33.1 & 33.2 \\
\hline Percent water uptake (\%) & 64 & 65 & 64 & 63 & 63 \\
\hline Cumulative \% Drug release (After $12 \mathrm{~h}$ ) & 96.37 & 96.24 & 96.21 & 96.18 & 95.94 \\
\hline Ex-vivo residence time $(\mathrm{h})$ & $11 \mathrm{~h} 21 \mathrm{~min}$ & $11 \mathrm{~h} 19 \mathrm{~min}$ & $11 \mathrm{~h} 23 \mathrm{~min}$ & $11 \mathrm{~h} 12 \mathrm{~min}$ & 11h $17 \mathrm{~min}$ \\
\hline
\end{tabular}

\section{CONCLUSION}

The concept of the sintering technique was studied in the development of controlled release mucoadhesive buccal tablets of ivabradine. From the data obtained experimentally, it was found that there was an increase in hardness, decrease in friability, and decrease in percent water uptake of the buccal tablets with the duration of exposure to various sintering temperatures. In addition, an increase in the sintering temperature and/or time of exposure to a particular temperature often decreased the drug release rate. Overall results indicated that formulation F3 SD (sintered at $60{ }^{\circ} \mathrm{C}$ for 3 h) which contains drug ivabradine, HPMC K100M, and carnauba wax in the ratio of $1: 6.6: 4.4$ showed acceptable physical parameters, mucoadhesive properties, surface $\mathrm{pH}$, desired therapeutic concentration with sustained drug release, effective in vitro permeation, stability on storage condition and satisfactory stability in human saliva.

Hence it can be concluded that the sintering technique can be used in the design of mucoadhesive buccal tablets of ivabradine HCL to prolong the duration of action, to overcome the problem of frequent dosing, avoid extensive first-pass metabolism, and ultimately its bioavailability.

\section{ACKNOWLEDGEMENT}

The authors wish to acknowledge Guru Nanak Institutions Technical Campus-School of pharmacy, Hyderabad, India, authority and Mr. B Sammaih of Osmania University, Hyderabad, India for providing research laboratory and instrumental facilities to carry out this work.

\section{FUNDING}

Nil

\section{AUTHORS CONTRIBUTIONS}

All the authors have contributed equally.

\section{CONFLICT OF INTERESTS}

The authors declare no conflict of interest.

\section{REFERENCES}

1. Miller NS. The use of mucoadhesive polymers in buccal drug delivery. Ad Drug Delivery Rev 2005;57:1666-91.

2. Mario J, Lacan MB. Influence of hydroxyl propyl- $\beta$-cyclodextrin complexation on piroxicam release from buccoadhesive tablets. Eur J Pharm Sci 2004;21:251-60.

3. Harris, Robinson JR. Drug delivery via the mucous membrane of oral cavity. J Pharm Sci 1992;81:1-10.
4. Tocker G. A method to study the kinetic of oral mucosal drug absorption for solution. Chem Pharm Bull 1998;40:679-83.

5. Junginger HE, Hoogstrate JA, Verhoef JC. Recent advances in buccal drug delivery and absorption in vitro and in vivo studies. J Controlled Release 1999;62:149-59.

6. Shojael H. Buccal mucosa as route for systemic drug delivery-a review. J Pharm Sci 1998;1:15-30.

7. Shafi S, Chowdary KA, Shivappa N, Hangargekar S. Formulation and evaluation of sintered matrix tablets of diltiazem hydrochloride. Int J Appl Pharm 2011;3:16-9.

8. Rao MRP, Shivpuje S, Godbole R, Shirsath C. Design and evaluation of sustained release matrix tablet using sintering technique. Int J Pharm Pharm Sci 2016;8:115-21.

9. Mohanty C. Sintering technique in pharmaceutical sciences: a brief review. Int J Pharmatech 2011;3:799-806.

10. Gordon F Rushworth, Philippe Lambrakis, Stephen J Leslie. Ivabradine: a new rate-limiting therapy for coronary artery disease and heart failure. Adv Drug Safety 2010;1:1-10.

11. Janet Marianne Jackson. Ivabradine-a novel treatment for chronic stable angina. Drugs Context 2008;4:135-52.

12. Lodhi M, Dubey A, Narayan R, Prabhu P, Priya S. Formulation and evaluation of buccal film of Ivabradine hydrochloride for the treatment of stable angina pectoris. Int J Pharma Investing 2013;3:47-53.

13. Dattatreya BU, Hiremath SN, Rao KS, Pawar D. Formulation and in vitro evaluation of Buccoadhesive tablets contaning ketoconazole inclusion complex with $\beta$-cyclodextrins. Res J Pharm Tech 2009;2:396-404.

14. Bhamre V, Sherkar D, Derle D, Narkhede M. Stability study of stavudine sintered matrix tablet. Int Res J Pharm 2013;4:182-5.

15. Bottenberg P, Cleymaet R, Muynek CD, Remon JP, Coomans D, Slop D, et al. Development and testing of bioadhesive, fluoridecontaining slow-release tablets for oral use. J Pharm Pharmacol 1991;43:457-64.

16. Kumar BP, Kavitha P, Devi KJ. Formulation design and evaluation of mucoadhesive buccal tablets of nitroglycerin. Int J Pharm Pharm Sci 2014;6:251-9.

17. Patel DM, Shah PM, Patel CN. Formulation and evaluation of bioadhesive buccal drug delivery of repaglinide tablets. Asian J Pharm 2012;6:171-9.

18. Mohanty C, Subrahmanyam KV, Jena TK, Sreekanth D. Use of sintering technique to sustain the release of atazanavir sulphate from gastro retentive floating matrix tablets. Am J Pharmatech Res 2015;5:587-607.

19. Bhowmik M, Baisya O, Deb J. Formulation and evaluation of sustained release matrix tablet of atenolol based on natural polymer. Res J Pharm Bio Chem Sci 2012;13:878-86. 
20. Uhumwangho MU, Ramana Murthy KV. Release characteristics of diltiazem hydrochloride wax-matrix granules-thermal sintering effect. J Appl Sci Manage 2011;15:365-70.

21. Penjuri SCB, Damineni S, Ravouru N. Design and development of buccal mucoadhesive drug delivery system of perindopril. J Pharm Sci 2015;8:37-49.

22. Biswal B, Karna N, Bhavsar B. Formulation and evaluation of Repaglinide buccal tablet: ex vivo bioadhesion study and ex vivo permeability study. J Appl Pharm Sci 2014;4:96-103.

23. Velmurugan S, Srinivas P. Formulation and evaluation of losartan potassium mucoadhesive buccal tablets. Asian J Pharm Clin Res 2013;6:125-30.
24. Goud K, Desai H, Pramod Kumar TM. Preparation and evaluation of a novel buccal adhesive system. AAPS PharmSciTech 2004;5:1-9.

25. Rowe RC, Sheskey PJ, Quinn ME. Handbook of pharmaceutical excipients, $6^{\text {th }}$ ed. London: Pharmaceutical Press; 2009.

26. Meka VS, Songa AS, Nail SR, Battu JR, Kukati L, Kolapalli VRN, et al. Thermal sintering: a novel technique in the design of gastro retentive floating tablets of proprannlol HCL and its evaluation. Invest Clin 2012;53:223-36.

27. Meka VS, Songa AS, Nail SR, Battu JR, Kolapalli VRN. Thermal sintering: a novel technique used in the design, optimization and biopharmaceutical evaluation of propranolol $\mathrm{HCl}$ gastric floating tablets. Drug Dev Ind Pharm 2014;40:33-45. 